\title{
12-year adherence to inhaled corticosteroids in adult-onset asthma
}

\author{
lida Vähätalo (1) ${ }^{1}$, Pinja Ilmarinen ${ }^{1}$, Leena E. Tuomisto (10), Minna Tommola (1) 1 , \\ Onni Niemelä ${ }^{2,3}$, Lauri Lehtimäki ${ }^{3,4}$, Pentti Nieminen ${ }^{5}$ and \\ Hannu Kankaanranta (10 ${ }^{1,3}$
}

Affiliations: ${ }^{1}$ Dept of Respiratory Medicine, Seinäjoki Central Hospital, Seinäjoki, Finland. ${ }^{2}$ Dept of Laboratory Medicine, Seinäjoki Central Hospital, Seinäjoki, Finland. ${ }^{3}$ Faculty of Medicine and Health Technology, Tampere University, Tampere, Finland. ${ }^{4}$ Allergy Centre, Tampere University Hospital, Tampere, Finland. ${ }^{5}$ Medical Informatics and Statistics Research Group, University of Oulu, Oulu, Finland.

Correspondence: lida Vähätalo, Dept of Respiratory Medicine, Seinäjoki Central Hospital, FIN-60220 Seinäjoki, Finland. Email: iida.vahatalodepshp.fi

ABSTRACT Adherence to inhaled corticosteroids (ICS) has been suggested to be poor but long-term follow-ups are lacking. The objective of the present study was to assess adherence to ICS treatment in patients with adult-onset asthma during 12-year follow-up.

A total of 181 patients with clinically confirmed, new-onset adult asthma were followed for 12 years as part of the Seinäjoki Adult Asthma Study. Adherence to ICS was assessed individually as the percentage of true dispensed ICS in micrograms per true prescribed daily ICS in micrograms over 12 years.

Mean 12-year adherence to ICS was $69 \%$ (mean \pm SD dispensed $2.5 \pm 1.8 \mathrm{~g}$ and prescribed $3.6 \pm 1.5 \mathrm{~g}$ budesonide equivalent per patient for 12 years), annual adherence varying between $81 \%$ (year 1 ) and $67 \%$ (year 12). Patients with good 12 -year adherence $(\geqslant 80 \%)$ used oral corticosteroids more often, and had add-on drugs in use and asthma-related visits to healthcare more often. In addition, they showed less reversibility in forced expiratory volume in $1 \mathrm{~s}$ and had higher peripheral blood neutrophil counts. However, lung function decline was steeper in patients with poorer adherence $(<80 \%)$ and this association remained in multiple linear regression analysis. No difference was found in symptom scores, blood eosinophil counts, exhaled nitric oxide or immunoglobulin E between the patients with different levels of adherence.

In patients with adult-onset asthma, adherence to ICS was moderate. Poorer adherence $(<80 \%)$ to ICS was associated with more rapid decline in lung function but was not associated to symptoms or markers of inflammatory endotypes.

@ERSpublications

Mean long-term adherence to ICS treatment is $69 \%$ in patients with confirmed adult-onset asthma. While good ICS adherence $(\geqslant 80 \%)$ is associated with features of more severe asthma, poorer adherence $(<\mathbf{8 0} \%)$ predicts more rapid lung function decline. http://bit.ly/37mvh74

Cite this article as: Vähätalo I, Ilmarinen P, Tuomisto LE, et al. 12-year adherence to inhaled corticosteroids in adult-onset asthma. ERJ Open Res 2020; 6: 00324-2019 [https://doi.org/10.1183/ 23120541.00324-2019].

This article has supplementary material available from openres.ersjournals.com

This study is registered at www.clinicaltrials.gov with identifier number NCT02733016.

Received: 21 Nov 2019 | Accepted after revision: 6 Feb 2020

Copyright $\odot$ ERS 2020. This article is open access and distributed under the terms of the Creative Commons Attribution Non-Commercial Licence 4.0. 


\section{Introduction}

Inhaled corticosteroids (ICS) are the basis of asthma treatment, reducing airway inflammation, improving lung function, controlling symptoms and reducing exacerbations [1, 2]. When evaluating whether the patients take their medication as prescribed, one of the most settled terms is "medication adherence", consisting of three essential elements: initiation, implementation and persistence [3]. Objective methods, such as electronic monitoring and electronic health records, or subjective methods, like patient reports, can be used to address medication adherence. Whichever the method used, adherence to ICS treatment has been suggested to be poor [4].

The age of asthma onset has been shown to be a significant factor in distinguishing the phenotypes of asthma $[5,6]$. Although a substantial proportion of asthma originates in childhood, recent data from the USA and Finland show that asthma diagnosed at adult age is common, and is in fact the dominant phenotype among women aged 35-40 years [7-9]. Patients with late-onset asthma are usually nonatopic and their response to corticosteroids is poorer than in patients with early-onset disease, and therefore they require more tailored medication [5,6]. Moreover, asthma rarely remits in patients with adult-onset asthma $[5,6,10,11]$. Even though many different characteristics of the adult-onset asthma phenotype have been described, adherence to medication remains unstudied.

Possible consequences of poor ICS adherence are decline in lung function, poorer symptom control and quality of life, and increase in asthma-related hospitalisations and costs [12-17]. Low adherence rates have also been associated with increased mortality and morbidity $[4,15,18]$. However, previous studies have usually been cross-sectional or short-term follow-ups and very little is known about the variation of medication adherence between and within persons in long-term treatment. In addition, to enhance reliable comparison of the results of adherence studies, variability in associated calculations and terms needs attention. Many studies based on medical records have used the best information available but the shortages in prescription or dispensation data have led to assumptions in adherence calculations [19-22]. In addition, previous studies have had shortages of information concerning diagnostic criteria, age of asthma onset and duration of asthma, which may all be factors influencing the results [22-25]. Though adherence to ICS has been $<50 \%$ in recent studies, we hypothesised that when patients have a confirmed diagnosis of asthma and regular ICS in use, they would have better medication adherence than previously described. Therefore, our aim was to assess adherence and its variability in long-term ICS treatment in real-life new-onset adult asthma patients with confirmed diagnoses during 12-year follow-up by using full coverage dispensing data and true prescribed medication.

\section{Methods}

\section{Study design and patients}

This study is part of Seinäjoki Adult Asthma Study (SAAS), which is a prospective 12-year follow-up study of 257 patients with diagnoses of new-onset adult asthma. Patients were consecutively included in the study during the period 1999-2002 if all of the following criteria were fulfilled: 1) new-onset asthma diagnosed by a respiratory specialist; 2) confirmation of diagnosis by lung function measurements showing variable or reversible obstruction; 3) symptoms of asthma; and 4) age $\geqslant 15$ years (tables S1 and S2). Importantly, patients with comorbidities or smoking history were not excluded. Study participants gave written informed consent to the study protocol approved by the ethics committee of Tampere University Hospital, Tampere, Finland. More than $94 \%$ of the patients diagnosed with novel asthma at the study site were recruited to the study [11]. In 2001, the study population represented $>38 \%$ of all novel diagnoses of asthma made in adults in the whole geographical area [26].

The study protocol has been published previously [27]. A schematic presentation of the study is shown in figure 1. The study was divided in two parts: collection of the original cohort (baseline) and the 12-year follow-up visit. At the baseline visit, data were collected on symptoms, lung function, demographics and initial medication [26]. Patients were followed for 12 years (mean 12.2 years, range 10.8-13.9 years) after the diagnostic visit. From the original cohort of 257 patients, 203 (79\%) returned to the 12 -year follow-up visit in which asthma status, medication, control and lung function were evaluated (supplementary material). All asthma-related visits and medication information were collected from the whole 12-year follow-up period from medical records. At the baseline visit, regular ICS medication was prescribed, and each patient received asthma education and self-management instructions according to Finnish Asthma Programme [28]. To ensure that the study population included only patients with regular ICS medication, we excluded patients for whom ICS was prescribed only as needed at any point in the follow-up period (figure 1).

\section{Computation of adherence}

The prescribed dose in each patient for the whole 12-year period was calculated based on medication records as previously described [29]. Shortly, we converted all prescribed ICS doses (ICS in both separate and 


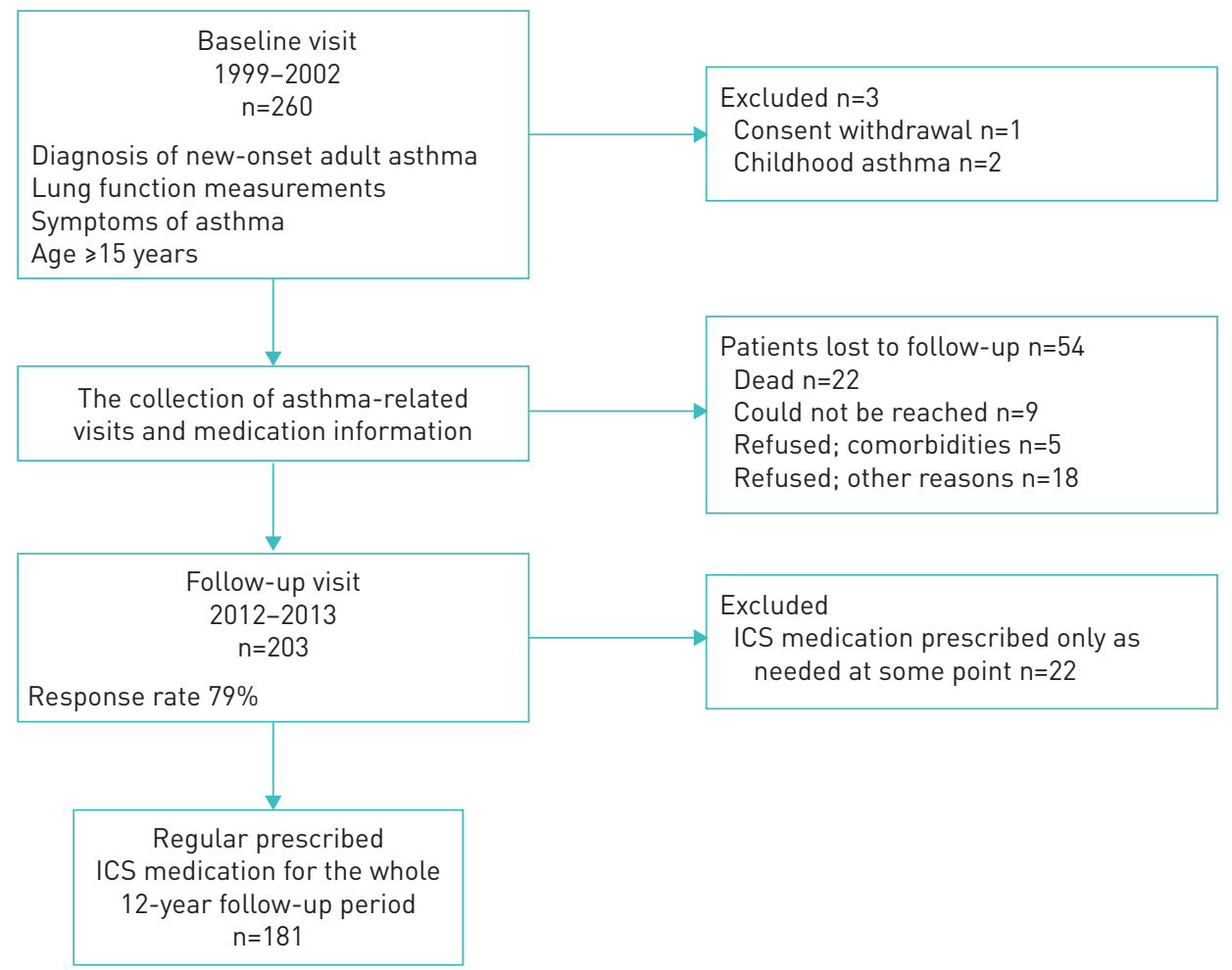

FIGURE 1 Flowchart of the study. ICS: inhaled corticosteroids.

combination inhalers) to budesonide equivalents and based on that information, calculated annual prescribed ICS medication for each patient. The dispensed ICS and oral corticosteroids were obtained from the Finnish Social Insurance Institution, which records all purchased medication from all Finnish pharmacies (supplementary material). Adherence to ICS was determined as previously described [3], consisting of initiation, implementation and persistence (supplementary material). The 12-year adherence was calculated by using formula 1 and annual adherence was calculated for each patient by using formula 2 (supplementary material). For comparing adherence groups, we used the most common cut-point of $80 \%[4,21,22]$.

$$
\begin{gathered}
\text { 12-year adherence }(\%)=\frac{12 \text {-year cumulative dispensed dose of ICS }(\mu \mathrm{g})}{12 \text {-year cumulative prescribed dose of ICS }(\mu \mathrm{g})} \times 100 \\
\text { Annual adherence }(\%)=\frac{\text { yearly dispensed dose of ICS }(\mu \mathrm{g})}{\text { yearly prescribed dose of ICS }(\mu \mathrm{g})} \times 100
\end{gathered}
$$

\section{Statistical analyses}

The data are presented as mean $\pm \mathrm{SD}$ or median (interquartile range) except in figures, where annual cumulative and daily doses are represented as mean \pm SEM for clarity. Comparison of groups with $\geqslant 80 \%$ or $<80 \%$ adherence was analysed by using independent-sample t-tests and Mann-Whitney U-tests for normally and non-normally distributed continuous variables, respectively, and Pearson Chi-squared or Fisher's exact test for categorical variables. To analyse differences between prescribed and dispensed ICS doses in both cumulative and annual manners, the individual patient's area under curve (AUC) was defined and mean AUC values were compared by using paired-samples t-tests. A multivariable logistic regression was performed to predict oral corticosteroid use and multiple linear regression analysis was performed to analyse factors associated with forced expiratory volume in $1 \mathrm{~s}\left(\mathrm{FEV}_{1}\right)$ decline as previously described [30]. The correlation matrix was analysed and explanatory variables not strongly correlated $(\mathrm{r}<0.7)$ were included in the analysis. In the linear regression analysis, outliers were removed to ensure homoscedasticity (supplementary material). A p-value $<0.05$ was regarded as statistically significant. Statistical analyses were performed by using IBM SPSS statistics software, version 24 (IBM SPSS, Armonk, NY, USA) and GraphPad Prism software, version 7.03 (GraphPad, La Jolla, CA, USA). 


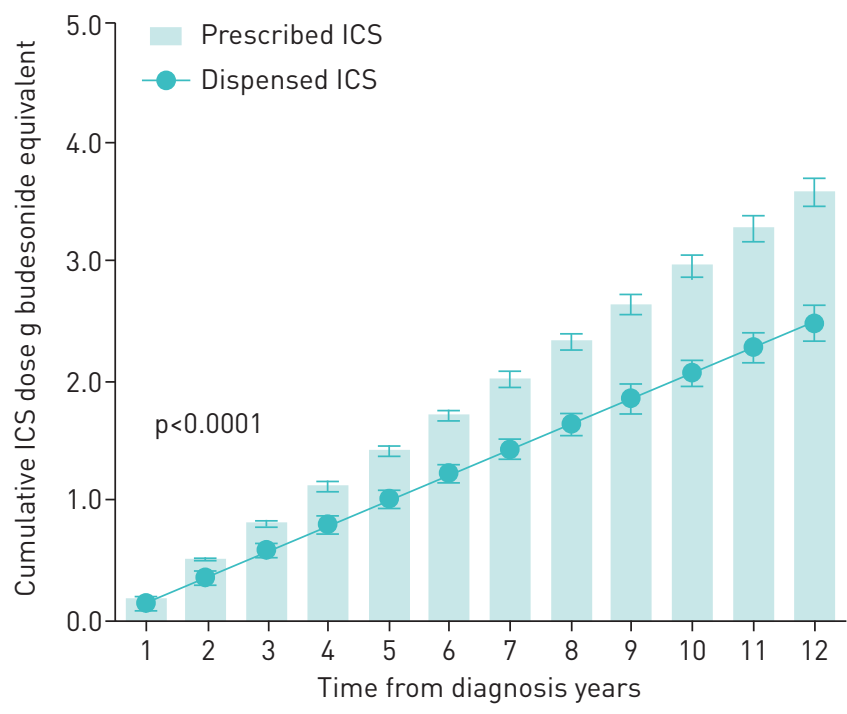

FIGURE 2 Annual prescribed and dispensed inhaled corticosteroids (ICS) shown as cumulative values (mean \pm SEM) ( $n=181)$. p-value re-presents difference between cumu-lative prescribed and dispensed ICS as defined by the area under the curve method and paired-sample t-test.

\section{Results}

\section{Patient characteristics}

The main characteristics of study patients are shown in table S3. The majority of the patients were female (60\%) and half of the patients were current or ex-smokers. At the follow-up visit, patients had higher body mass index (BMI), $\mathrm{FEV}_{1}$ and forced vital capacity (FVC), but lower blood eosinophil counts and symptom scores (Airway Questionnaire 20) than at the baseline.

\section{Long-term adherence for 12 years}

The mean 12-year adherence to ICS was $69 \%$ across all 181 patients (dispensed ICS $2.5 \pm 1.8 \mathrm{~g}$ and prescribed ICS $3.6 \pm 1.5 \mathrm{~g}$ budesonide equivalent per patient for 12 years) (figure 2). To visualise the variation in the long-term adherence in the whole study population, we determined annual adherence for each patient individually. The mean annual adherence gradually declined from year 1 (81\%) to year 12 (67\%) (figure 3). The prescribed annual daily ICS doses for study patients were high (on average, $>800 \mu \mathrm{g}$ ) but patients dispensed significantly lower doses (on average, $<800 \mu \mathrm{g}$ budesonide equivalent) of ICS during the 12-year follow-up (figure 4). If calculated by using the maximum value of the dose range in the prescription instead of the mean value of the range (e.g. in a subject who was prescribed budesonide/ formoterol $200 / 6 \mu \mathrm{g}$, one to two puffs twice a day), it affected the mean 12 -year adherence by $-4.4 \%$. Smoking status or comorbidities did not affect the mean 12-year adherence values (data not shown).

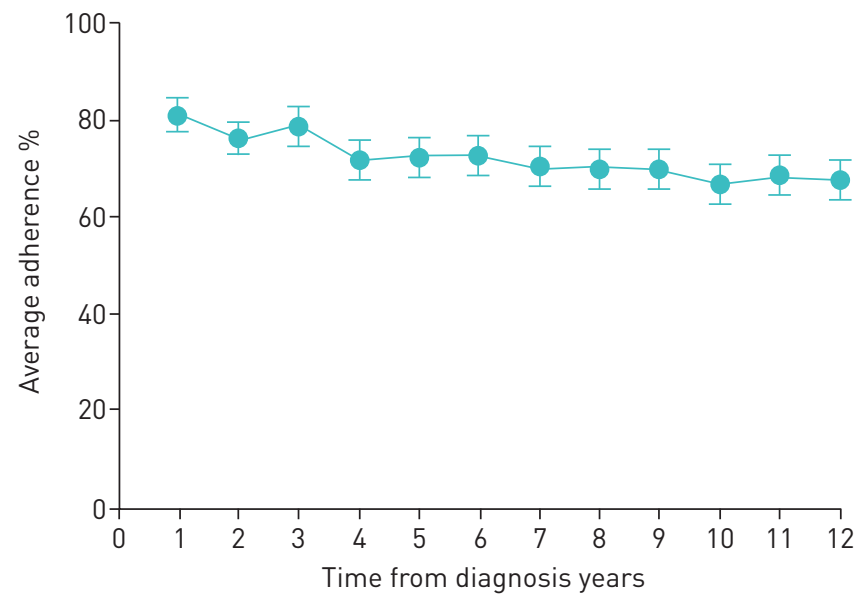

FIGURE 3 The average annual adherence (mean士SEM) during the 12-year follow-up period ( $n=181)$. 


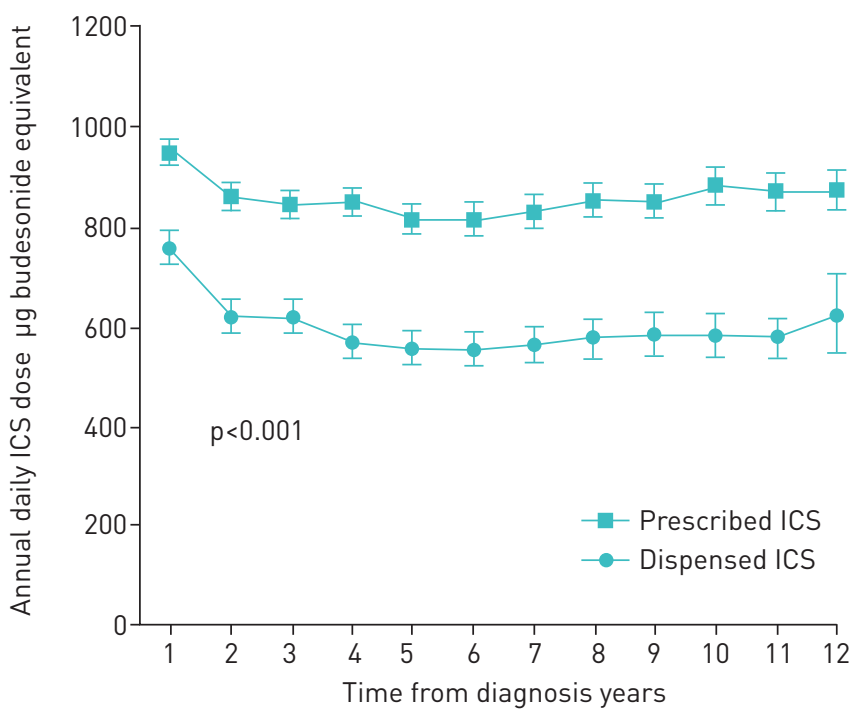

FIGURE 4 Average annual prescribed and dispensed daily doses of inhaled corticosteroids (ICS) in the 12-year follow-up periods (mean士SEM) ( $n=181$ ). $p$-value represents difference between cumulative prescribed and dispensed ICS as defined by area under the curve method and paired-samples t-test.

\section{Changes in adherence over 12 years}

The proportion of adherent patients $(\geqslant 80 \%)$ was highest during the first year after the diagnosis (figure 5). Of the study patients, 17 (9\%) had annual ICS adherence rates $>80 \%$ during the whole 12-year follow-up period. In addition, $55(30 \%)$ of the patients had annual adherence that was always $>50 \%$. Annual nonadherence (annual adherence rate $0 \%$ ) ranged from $6.6 \%$ to $20.4 \%$ but on average, $14.5 \pm 4.6 \%$ of the patients were nonadherent during the 12 years (figure $5 \mathrm{~b}$ ). The total number of patients having an annual nonadherent period at least once was 67 (37\%), and 1\% of the patients failed to collect their first treatment prescription (initiation) [3] and were fully nonadherent to ICS therapy during the whole 12-year follow-up period.

\section{Comparison of patients with good or poor 12-year adherence}

Average prescribed ICS doses were similar in patients with better $(\geqslant 80 \%)$ and poorer $(<80 \%) 12$-year adherence but dispensed ICS doses were only one-third in patients with poorer adherence (table 1). Patients with good 12 -year adherence $(\geqslant 80 \%)$ more often had a long-acting $\beta_{2}$-agonist (LABA) or any other add-on drug in use, more often reported oral corticosteroid courses and were dispensed higher amounts of oral corticosteroids during the follow-up (table 2 and supplementary material). In addition, they showed less $\mathrm{FEV}_{1}$ reversibility, had higher peripheral blood neutrophils (table 3), had a higher number of asthma-related contacts to healthcare and tended to have more unplanned hospital in-patient days due to asthma (table 2). However, the decline in lung function was steeper in patients with poorer adherence $(<80 \%)$. There was no difference in symptom scores or other inflammatory markers (blood eosinophils, exhaled nitric oxide fraction $\left(F_{\mathrm{ENO}}\right)$ or IgE) between the subgroups with different 12-year adherences (tables 2 and 3). If a lower cut-point for adherence was used, the results were largely similar.
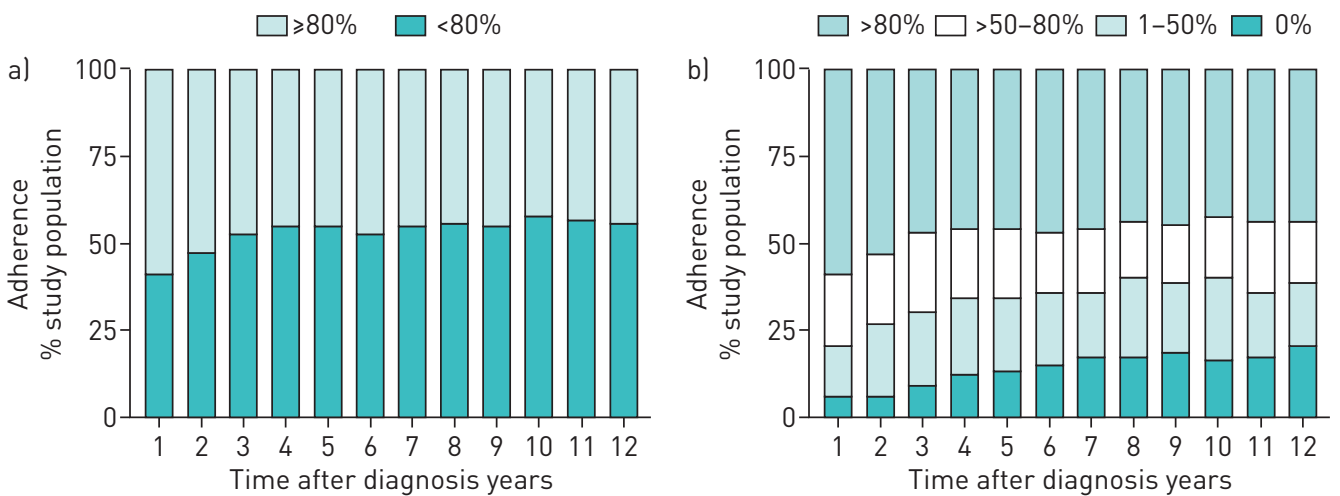

FIGURE 5 Annual adherence rates a) when using $80 \%$ adherence as a cut-off ( $n=181$ ); and b) when dividing patients into high, moderate or low adherence, and non-adherence during the 12-year follow-up. 


\begin{tabular}{|c|c|c|c|}
\hline & \multicolumn{3}{|c|}{ 12-year adherence } \\
\hline & $\begin{array}{l}\text { Good } \\
\text { adherence }\end{array}$ & $\begin{array}{l}\text { Poor } \\
\text { adherence }\end{array}$ & p-value \\
\hline Age years mean $\pm s D$ & $61 \pm 12$ & $58 \pm 14$ & $0.065^{\S}$ \\
\hline Female sex & $52(63.4 \%)$ & $56(56.6 \%)$ & $0.365^{f}$ \\
\hline BMI $\mathrm{kg} \cdot \mathrm{m}^{-2}$ & $28.1(24.3-31.3)$ & $28.4(24.6-31.2)$ & $0.640^{\# \#}$ \\
\hline Smokers $^{+}$ & $40(48.8 \%)$ & $51(51.5 \%)$ & $0.766^{f}$ \\
\hline Smoking history pack-years & $18(9-33)$ & $17(6-29)$ & $0.407^{\# \#}$ \\
\hline $\begin{array}{l}\text { Smoking history } \geqslant 10 \text { pack-years and post-BD } \\
\text { FEV }_{1} / \text { FVC }<0.7\end{array}$ & $12(30 \%)$ & $21(42 \%)$ & $0.276^{f}$ \\
\hline Number of comorbidities & $1(0-3)$ & $1(0-2)$ & $0.487^{\# \#}$ \\
\hline Daily SABA & $13(15.9 \%)$ & $8(8.1 \%)$ & $0.161^{f}$ \\
\hline Daily LABA & $54(65.9 \%)$ & $41(41.4 \%)$ & $0.002^{f}$ \\
\hline Daily LTRA & $18(22 \%)$ & $8(8.2 \%)$ & $0.011^{f}$ \\
\hline Daily theophylline & $4(4.9 \%)$ & $0(0 \%)$ & $0.040^{f}$ \\
\hline Daily tiotropium & $5(6.1 \%)$ & $3(3.0 \%)$ & $0.471^{f}$ \\
\hline Daily add-on drug & $57(69.5 \%)$ & $44(44.4 \%)$ & $0.001^{f}$ \\
\hline $\begin{array}{l}\text { Average prescribed ICS daily dose over } 12 \text { years } \mu \mathrm{g} \\
\text { budesonide equivalents }\end{array}$ & 810 (611-1043) & 805 (610-967) & $0.496^{\# \#}$ \\
\hline $\begin{array}{l}\text { Average dispensed ICS daily dose over } 12 \text { years } \mu \mathrm{g} \\
\text { budesonide equivalents }\end{array}$ & 803 (616-1075) & $320(146-472)$ & $<0.001^{\# \#}$ \\
\hline
\end{tabular}

Data are presented as $\mathrm{n}(\%)$ or median (interquartile range), unless otherwise stated. BMI: body mass index; $\mathrm{BD}$ : bronchodilator; $\mathrm{FEV}_{1}$ : forced expiratory volume in $1 \mathrm{~s}$; $\mathrm{FVC}$ : forced vital capacity; SABA: short-acting $\beta_{2}$-agonist; LABA: long-acting $\beta_{2}$-agonist; LTRA: leukotriene receptor antagonist; ICS: inhaled

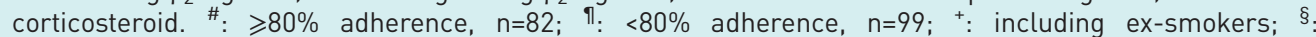
independent-samples t-test; ${ }^{f}$ : Fisher's exact test; ${ }^{\# \#}$ : Mann-Whitney U-test.

However, patients with $\geqslant 50 \%$ adherence were more obstructive (lower $\mathrm{FEV}_{1} / \mathrm{FVC}$ ) but did not differ by lung function decline (table S4). Furthermore, we evaluated whether those with one or more completely nonadherent years differed from those without nonadherent years and the results were similar to the main results of the study (table S5).

Patients with $\geqslant 80 \%$ adherence reported using oral corticosteroids more often during the follow-up and after adjusting this finding for age $>50$ years, sex, $\mathrm{BMI}>30 \mathrm{~kg} \cdot \mathrm{m}^{-2}$, pre- $\mathrm{FEV}_{1}$ at follow-up visit and COPD, the association remained (OR 1.99, 95\% CI 1.02-3.87; $\mathrm{p}=0.043$ ). In addition, we carried out multiple linear regression analysis to find out whether poor adherence predicts accelerated lung function decline when adjusted for age, $\Delta \mathrm{BMI}$ during the follow-up period, sex, $F_{\mathrm{ENO}}>20 \mathrm{ppb}$, smoking history $\geqslant 10$ pack-years, blood eosinophils, use of oral corticosteroid courses, $\mathrm{FEV}_{1} \%$ pred at baseline and $\Delta \mathrm{FEV}_{1}$ (baseline-maximum ${ }_{0-2.5}$ ) (table $\mathrm{S} 6$ ). After adjustments, poorer adherence $(<80 \%)$ remained a significant predictor for $\mathrm{FEV}_{1}$ (in millilitres) decline.

\section{Discussion}

In this study, we evaluated both annual and 12-year adherence to ICS from diagnosis to a 12-year follow-up visit in patients with adult-onset asthma. Mean 12-year adherence to ICS was 69\%. Patients with good 12-year adherence $(\geqslant 80 \%)$ more often used LABA daily, and had more oral corticosteroid courses and asthma-related contacts to healthcare. In addition, they showed less reversibility of $\mathrm{FEV}_{1}$ and had higher peripheral blood neutrophil counts. However, lung function decline during the follow-up period was steeper in patients with poorer long-term adherence $(<80 \%)$. These results suggest that in patients with confirmed diagnoses of adult-onset asthma, the mean adherence to ICS is moderate but variance in annual ICS adherence is also common in long-term treatment. Even though good ICS adherence $(\geqslant 80 \%)$ was, overall, associated with features of more severe asthma, poorer adherence $(<80 \%)$ predicted more rapid lung function decline.

Our study showed that the mean 12-year ICS adherence was 69\%, which is in line with the previous studies where overall adherence to asthma treatment ranged 30-70\% [4]. However, adherence was higher in our study than in other adherence studies based on electronic medical records, where adherence ranged $21-52 \%$ [23-25, 31-33]. Previous short-term studies have suggested a decline in lung function or reductions in symptom control and quality of life because of poor adherence $[12,13,15,16,31]$. In our study, for the first time, poorer adherence $(<80 \%)$ was found to predict more rapid lung function decline long term. It might be 


\begin{tabular}{|c|c|c|c|}
\hline & \multicolumn{3}{|c|}{ 12-year adherence } \\
\hline & Good adherence ${ }^{\#}$ & Poor adherence ${ }^{\pi}$ & p-value \\
\hline \multicolumn{4}{|l|}{ Symptoms of asthma } \\
\hline AQ20 score & $4(2-7)$ & $4(1-8)$ & 0.583 \\
\hline ACT score & $21(19-24)$ & $21(19-24)$ & 0.790 \\
\hline CAT & $12(7-18)$ & $11(6-17)$ & 0.473 \\
\hline \multicolumn{4}{|l|}{ Burden of asthma } \\
\hline $\begin{array}{l}\text { Self-reported use of oral corticosteroid courses for } \\
\text { asthma }\end{array}$ & $34(42.5 \%)$ & $26(26.3 \%)$ & $0.026^{f}$ \\
\hline Dispensed oral corticosteroid for asthma ${ }^{+} \mathrm{mg} \cdot \mathrm{year}^{-1}$ & $101(11-249)$ & $51(0-165)$ & $0.019^{\# \#}$ \\
\hline At least one hospitalisation due to asthma & $14(17.1 \%)$ & $13(13.1 \%)$ & $0.532^{f}$ \\
\hline Three or more sick leaves during the past 2 years & $3(4.8 \%)$ & $4(5.2 \%)$ & $>0.999^{f}$ \\
\hline Emergency department visits & $0(0-0)$ & $0(0-0)$ & $0.708^{\# \#}$ \\
\hline Fulfils severe asthma criteria according to ERS/ATS & $6(7.3 \%)$ & $6(6.1 \%)$ & $0.772^{f}$ \\
\hline Hospital days, asthma-related ${ }^{\S}$ & $0(0-0)$ & $0(0-0)$ & $0.051^{\# \#}$ \\
\hline Range & $0-64$ & $0-12$ & \\
\hline Hospital days, any respiratory reason ${ }^{\S}$ & $0(0-0)$ & $0(0-0)$ & $0.072^{\# \#}$ \\
\hline Range & $0-64$ & $0-37$ & \\
\hline Asthma control visits & $7(4-11)$ & $6(3-9)$ & $0.023^{\# \#}$ \\
\hline Asthma-related visits to healthcare & $19(12-28)$ & $11(8-19)$ & $<0.001^{\# \#}$ \\
\hline \multicolumn{4}{|c|}{$\begin{array}{l}\text { Data are presented as median (interquartile range), unless otherwise stated. Symptoms of asthma were } \\
\text { observed at the } 12 \text {-year follow-up visit. Sick leaves were observed in the } 2 \text { years before the follow-up visit. } \\
\text { Self-reported use of oral corticosteroids, hospitalisations and hospital days were examined during the } \\
\text { whole } 12 \text {-year follow-up period. AQ20: Airway Questionnaire 20; ACT: Asthma Control Test; CAT: COPD } \\
\text { Assessment Test; ERS: European Respiratory Society; ATS: American Thoracic Society. \#: } \geqslant 80 \% \\
\text { adherence, } n=82 \text {. ": }<80 \% \text { adherence, } n=99 .^{+} \text {: data obtained from the Finnish Social Insurance Institution } \\
\text { and were divided by the years of follow-up (supplementary material); statistical significance considering } \\
\text { symptoms of asthma were evaluated by independent-samples Mann-Whitney U-test. } \S: \text { unplanned. } \\
\text { f: Pearson Chi-squared test. \#\#: independent-samples Mann-Whitney U-test. }\end{array}$} \\
\hline
\end{tabular}

argued whether the annual difference of $6 \mathrm{~mL}$ in median values is clinically significant but most patients had chronic asthma, which rarely remits, and therefore, the cumulative effect in the long term may have clinical significance. Even though patients with poorer adherence otherwise showed features of less severe disease (e.g. less use of add-on drugs and fewer healthcare visits), indicating that these patients may be less adherent because of the feeling of not needing medication, poor adherence seems to have harmful long-term effects on lung function. Given that reduced lung function is a risk factor for exacerbations [34], these patients might predispose themselves to exacerbations in the long term by not taking their medication. In our study as well as in the previous ones [30,35], increased eosinophilic inflammation has been shown to associate with more rapid decline in lung function, but in our study, no difference was found in the level of blood eosinophils or $F_{\mathrm{ENO}}$ between the subgroups with different levels of adherence. However, the blood eosinophil and $F_{\mathrm{ENO}}$ values were based on a single time-point (12-year follow-up visit), leaving the possibility that the level of inflammation may have been higher for some period during the follow-up in these patients, providing a possible mechanism for steeper lung function decline in less adherent patients.

Despite the mean 12-year ICS adherence being as high as 69\%, annual nonadherence was observed in $37 \%$ of the patients at least once during the 12-year follow-up period and only $9 \%$ of the patients had annual adherence that was always $>80 \%$. In summary, individual patients appeared to use ICS periodically under and over the prescribed doses but on average, patients adhered to ICS treatment well during long-term treatment. As symptoms of asthma and airway limitation vary over time [2], patients' adherence behaviour may reflect the nature of asthma as a disease. The reasons behind relatively high rates of adherence in Finnish adult asthma patients are various: $65 \%$ reimbursement of asthma medicine expenses, relatively low medicine prices, prescriptions for 1-2 years at time (medication available when needed), cost-free renewal of prescriptions, public health services available for all, lung function measurements at asthma contacts and guidance on correct inhaler use by, for example, specialised asthma nurses and the Finnish asthma programme [28].

Previous studies on adherence to asthma medication have been short-term follow-ups, the most common follow-up time being 12 months [23, 25, 31-33]. SAAS is a 12-year, real-life follow-up study of new-onset adult asthma patients giving information on adherence to ICS over an exceptionally long period. In addition, many 


\begin{tabular}{|c|c|c|c|}
\hline & \multicolumn{3}{|c|}{ 12-year adherence } \\
\hline & Good adherence $^{\#}$ & Poor adherence & $\mathrm{p}$-value \\
\hline \multicolumn{4}{|l|}{ Lung function at follow-up } \\
\hline Pre-BD FEV ${ }_{1} \%$ pred & 87 (75-99) & $86(75-94)$ & 0.398 \\
\hline Pre-BD FVC \% pred & $97(87-108)$ & $96(87-106)$ & 0.374 \\
\hline Pre-BD FEV $1 / F V C$ & $0.73(0.67-0.78)$ & $0.74(0.65-0.79)$ & 0.730 \\
\hline Post-BD FEV $1 \%$ pred & 90 (79-99) & $89(81-96)$ & 0.682 \\
\hline Post-BD FVC \% pred & $99(85-108)$ & 97 (88-105) & 0.416 \\
\hline Post-BD FEV $1 / F V C$ & $0.74(0.68-0.79)$ & $0.76(0.68-0.81)$ & 0.320 \\
\hline $\mathrm{FEV}_{1}$ reversibility $\mathrm{mL}$ & 65 (7.5-123) & $100(40-170)$ & 0.010 \\
\hline $\mathrm{FEV}_{1}$ reversibility $\%$ initial $\mathrm{FEV}_{1}$ & $2.7(0.29-5.0)$ & $3.8(1.6-6.8)$ & 0.039 \\
\hline \multicolumn{4}{|l|}{ Lung function change } \\
\hline$\Delta \mathrm{FEV}_{1} \%$ pred.year ${ }^{-1}$ & $-0.39(-0.88-0.40)$ & $-0.54(-1.2-0.0)$ & 0.026 \\
\hline$\Delta \mathrm{FEV}_{1} \mathrm{~mL} \cdot \mathrm{year}^{-1}$ & $-40(-56--22)$ & $-46(-81--26)$ & 0.050 \\
\hline$\Delta$ FVC $\%$ pred.year ${ }^{-1}$ & $0.11(-0.47-0.82)$ & $-0.21(-0.87-0.45)$ & 0.034 \\
\hline$\Delta \mathrm{FVC} \mathrm{mL} \cdot$ year $^{-1}$ & $-32(-56--10)$ & $-36(-64--13)$ & 0.329 \\
\hline$\Delta \mathrm{FEV}_{1} / \mathrm{FVC}$ year $^{-1}$ & $-0.005(-0.008--0.0001)$ & $-0.005(-0.008--0.002)$ & 0.316 \\
\hline \multicolumn{4}{|l|}{ Markers of inflammation } \\
\hline Blood eosinophils $\times 10^{9} \mathrm{~L}^{-1}$ & $0.17(0.09-0.28)$ & $0.18(0.10-0.27)$ & 0.549 \\
\hline Total IgE kU. $\mathrm{L}^{-1}$ & $71(24-165)$ & $56(26-178)$ & 0.956 \\
\hline$F_{\text {ENO }}(p p b)$ & $10(5-19)$ & $11(5-18)$ & 0.683 \\
\hline Blood neutrophils $\times 10^{9} \mathrm{~L}^{-1}$ & $4.2(3.5-5.3)$ & $3.5(2.7-4.6)$ & 0.001 \\
\hline $\mathrm{IL}-6 \mathrm{pg} \cdot \mathrm{mL}^{-1}$ & $1.9(1.2-3.2)$ & $1.8(1.1-3.3)$ & 0.537 \\
\hline hsCRP $\mathrm{mg} \cdot \mathrm{L}^{-1}$ & $1.0(0.48-2.3)$ & $1.4(0.62-2.9)$ & 0.224 \\
\hline
\end{tabular}

Data are presented as median (interquartile range) unless otherwise stated. Statistical significance was evaluated by independent-samples Mann-Whitney U-test. BD: bronchodilator; FEV ${ }_{1}$ : forced expiratory volume in $1 \mathrm{~s}$; FVC: forced vital capacity; $F_{E N O}$ : exhaled nitric oxide fraction; IL: interleukin; hsCRP: high-sensitivity C-reactive protein. ${ }^{\#}: \geqslant 80 \%$ adherence, $n=82 ;{ }^{\uparrow}:<80 \%$ adherence, $n=99$.

studies only included populations from healthcare organisations or insurance databases, meaning that the patient cohort is selected and patients outside these databases are excluded [24, 31, 32]. SAAS has collected extensive 12-year follow-up data including information on all prescribed and dispensed asthma medication of the study patients. Moreover, all new-onset adult asthmatics, i.e. patients with comorbidities and a history of smoking, were included and therefore, the study cohort represents the general adult population with asthma well [26].

Information on the duration of asthma, age of asthma onset and diagnostic criteria used were missing from the previous adherence studies, all of which are factors that could influence adherence [23, 24, 31-33, 36]. In the studies using administrative or other register data only, asthma diagnosis has typically been based on International Classification of Diseases codes found from these records [25, 36, 37], causing unreliability and variation in the correctness of asthma diagnosis. For example, a study in the USA [23] identified that only $8.8 \%$ of the patients continued to refill their prescriptions from the index date to year's end, whereas in another study [38], $\sim 50 \%$ of the patients did not renew their initial prescription. In these studies, the average adherence to ICS was poor, which may be partly explained by the absence of strict diagnostic criteria and confirmed asthma diagnosis, leading to inclusion of nonasthmatic subjects in the study. Conversely, many studies based on health records have used the best information available but shortages in prescription or dispensation data have led to assumptions in adherence calculations [19-22]. For example, the total day's supply is often based on pharmacists' estimation, typically assuming the maximum use of prescribed doses (e.g. one to two puffs once or twice a day assumed to be four puffs a day), which can lead to underestimation of adherence [20]. Moreover, BLAIs et al. [39] noted that when one of the most commonly used measures adherence (proportion of days covered [37]) from administrative data is used, it assumes that the medication is prescribed for chronic daily use, and in cases of suboptimal prescribing, it may lead to underestimation of adherence. In our study, the diagnosis of asthma was made by a respiratory physician, and was based on both typical symptoms and variable or reversible airway obstruction in lung function measurements. Regarding adherence calculations, we examined all prescribed and refilled ICS doses and dose changes for 12 years based on individual patients' medical records and dispensation data, and all patients had regular prescribed ICS medication for the whole follow-up period (supplementary material). 
Because our study was based on medical records and pharmacy dispensation data, it has some limitations. Firstly, the medical records were not always complete (shortage of physicians' notes, e.g. missing dose information) but prescribed medication was calculated based on previously confirmed information. Secondly, dispensing of a medicine does not guarantee patients' actual use of ICS nor good inhalation technique. Thirdly, some information on patients' behaviour regarding stepping medication up and down was not available in our study (i.e. patients may have used an action plan during influenza or an exacerbation and doubled the ICS dose). Despite these limitations, electronic medical records are preferred because they enable long observation periods in the assessment of adherence and they are commonly used in evaluation of adherence [4]. Moreover, electronic monitoring devices (EMDs), such as smart inhalers, are the gold standard in precise and reliable monitoring of adherence. Our results showed that adherence to ICS decreased most rapidly during the first 4 years of follow-up and this would potentially be an optimal point for EMD studies.

The results of earlier studies have shown many negative associations as a result of patients' poor ICS adherence $[4,12,15]$. In this study, patients with poorer long-term ICS adherence used remarkably lower ICS doses, less frequently used LABA on daily basis and were less often hospitalised compared to patients with better 12-year ICS adherence. This suggests that patients with poorer adherence $(<80 \%)$ may have had milder asthma compared to patients with better adherence $(\geqslant 80 \%)$. Therefore, undesirable treatment outcomes should not be regarded only as consequences of poor adherence, since even patients with good adherence may suffer from these outcomes. Patients with better adherence had also higher blood neutrophil counts and showed features of more severe asthma, indicating that some patients may have had non-T2-mediated disease. Future studies should pay more attention to the reasons why undesirable outcomes emerge in patients with good adherence to ICS and whether there would be more effective treatment strategies for these patients [40].

Taken together, we show, for the first time, long-term, 12-year adherence data of patients with adult-onset asthma based on true prescribed and dispensed medication. Clinical patients with objectively confirmed diagnoses of new-onset adult asthma had, on average, moderate adherence to long-term ICS treatment. This suggests that when evaluating patients' adherence, it is important to ensure that study population includes only patients with reliable asthma diagnoses and need for regular ICS medication [36]. In addition, when assessing long-term adherence to ICS, major variability in annual rates of adherence should be considered and, therefore, follow-up periods should be set long enough. In future, adult- and childhood-onset asthma patients should be compared to gain better understanding of the characteristics of adherence in different phenotypes. The new information about adherence characteristics in phenotypes would enhance possibilities to intervene with patients who show signs of inefficient treatment. All in all, our results show that poor adherence to ICS treatment may lead to steeper decline in lung function, which may have negative consequences in the long term. Our findings, therefore, also support performing spirometry regularly, as recommended by the Global Initiative for Asthma. Otherwise, patients with good adherence showed features of more severe asthma in comparison to less adherent patients. These patients need new strategies for their asthma treatment when regular controller medication seems not to be effective enough.

Acknowledgements: Aino Sepponen (Dept of Respiratory Medicine, Seinäjoki Central Hospital, Seinäjoki, Finland) is gratefully acknowledged for her help through all stages of this work.

Author contributions: H. Kankaanranta, L.E. Tuomisto, O. Niemelä and P. Ilmarinen conceived and designed the study; I Vähätalo, P. Ilmarinen and P. Nieminen analysed the data; H. Kankaanranta, L.E. Tuomisto, O. Niemelä, P. Ilmarinen and I Vähätalo collected the data; I Vähätalo, P. Ilmarinen and H. Kankaanranta wrote the manuscript; and all authors reviewed and edited the manuscript.

Conflict of interest: I. Vähätalo reports personal fees for a lecture from AstraZeneca outside the submitted work. P. Ilmarinen reports a grant for analysis and write-up of a study and a fee for a lecture from AstraZeneca, and personal fees for lectures from Mundipharma, GlaxoSmithKline and Orion, outside the submitted work. L.E. Tuomisto reports reimbursement of costs for attending international congresses from Chiesi, Boehringer Ingelheim, Orion Pharma and TEVA; reimbursement of costs for a lecture from AstraZeneca; and attendance of an advisory board meeting for Novartis, outside the submitted work. M. Tommola reports personal fees for lectures from AstraZeneca, Pfizer and Chiesi; personal fees for lectures and consultation from Boehringer Ingelheim; and grants from the Orion Research Foundation, outside the submitted work. O. Niemelä has nothing to disclose. L Lehtimäki reports personal fees from ALK, AstraZeneca, Boehringer Ingelheim, Chiesi, GSK, Novartis, Mundipharma, OrionPharma, SanofiGenzyme and Teva, outside the submitted work. P. Nieminen has nothing to disclose. H. Kankaanranta reports fees for lectures and consulting, costs for attending an international congress, and a research grant to their institution from AstraZeneca; fees for consulting from Chiesi Pharma AB, SanofiGenzyme and GlaxoSmithKline; fees for lectures and consulting, and costs for attending international congresses from Boehringer Ingelheim and Orion Pharma; fees for lectures and consulting from Novartis; and fees for lectures from Mundipharma, outside the submitted work.

Support statement: This study is funded by the Tampere Tuberculosis Foundation (Tampere, Finland), the Finnish Anti-Tuberculosis Association Foundation (Helsinki, Finland), the Research Foundation of the Pulmonary Diseases (Helsinki, Finland), the Ida Montini Foundation (Kerava, Finland), the Pirkanmaa Regional Fund of the Finnish 
Cultural Foundation (Helsinki, Finland), Allergy Research Foundation (Helsinki, Finland), Competitive State Research Financing of the Expert Responsibility Area of Tampere University Hospital (Tampere, Finland) and the Medical Research Fund of Seinäjoki Central Hospital (Seinäjoki, Finland). None of the sponsors had any involvement in the planning, execution, drafting or write-up of this study. Funding information for this article has been deposited with the Crossref Funder Registry.

\section{References}

1 Derendorf H, Nave R, Drollmann A, et al. Relevance of pharmacokinetics and pharmacodynamics of inhaled corticosteroids to asthma. Eur Respir J 2006; 28: 1042-1050.

2 Global Initiative for Asthma. Global Strategy for Asthma Management and Prevention 2016. Available from: www. ginasthma.org.

3 Vrijens B, Dima AL, Van Ganse E, et al. What we mean when we talk about adherence in respiratory medicine. J Allergy Clin Immunol Pract 2016; 4: 802-812.

4 Engelkes M, Janssens HM, de Jongste JC, et al. Medication adherence and the risk of severe asthma exacerbations: a systematic review. Eur Respir J 2015; 45: 396-407.

5 Wenzel SE. Asthma phenotypes: the evolution from clinical to molecular approaches. Nat Med 2012; 18: 716-725.

6 Ilmarinen P, Tuomisto LE, Kankaanranta H. Phenotypes, risk factors and mechanisms of adult-onset asthma. Mediators Inflamm 2015; 2015: 1-19.

7 Kankaanranta H, Israel E. What patients can tell us about their asthma. J Allergy Clin Immunol Pract 2019; 7 : 906-907.

8 Sood A, Qualls C, Schuyler M, et al. Adult-onset asthma becomes the dominant phenotype among women by age 40 years. Ann Am Thorac Soc 2013; 10: 188-197.

9 Kankaanranta H, Tuomisto LE, Ilmarinen P. Age-specific incidence of new asthma diagnoses in Finland. J Allergy Clin Immunol Pract 2017; 5: 189-191.e3.

10 Burgess JA, Matheson MC, Gurrin LC, et al. Factors influencing asthma remission: a longitudinal study from childhood to middle age. Thorax 2011; 66: 508-513.

11 Tuomisto LE, Ilmarinen P, Niemela O, et al. A 12-year prognosis of adult-onset asthma: Seinäjoki Adult Asthma Study. Respir Med 2016; 117: 223-229.

12 Suissa S, Ernst P, Kezouh A. Regular use of inhaled corticosteroids and the long term prevention of hospitalisation for asthma. Thorax 2002; 57: 880-884.

13 Kandane-Rathnayake RK, Matheson MC, Simpson JA, et al. Adherence to asthma management guidelines by middle-aged adults with current asthma. Thorax 2009; 64: 1025-1031.

14 Rust G, Zhang S, McRoy L, et al. Potential savings from increasing adherence to inhaled corticosteroid therapy in Medicaid-enrolled children. Am J Manag Care 2015; 21: 173-180.

15 Gamble J, Stevenson M, McClean E, et al. The prevalence of nonadherence in difficult asthma. Am J Respir Crit Care Med 2009; 180: 817-822.

16 Williams LK, Pladevall $\mathrm{M}, \mathrm{Xi} \mathrm{H}$, et al. Relationship between adherence to inhaled corticosteroids and poor outcomes among adults with asthma. J Allergy Clin Immunol 2004; 114: 1288-1293.

17 Zafari Z, Lynd LD, FitzGerald JM, et al. Economic and health effect of full adherence to controller therapy in adults with uncontrolled asthma: a simulation study. J Allergy Clin Immunol 2014; 134: 908-915.

18 Pauwels RA, Pedersen S, Busse WW, et al. Early intervention with budesonide in mild persistent asthma: a randomised, double-blind trial. Lancet 2003; 361: 1071-1076.

19 Laforest L, Belhassen M, Devouassoux G, et al. Long-term inhaled corticosteroid adherence in asthma patients with short-term adherence. J Allergy Clin Immunol Pract 2016; 4: 890-899.

20 Makhinova T, Barner JC, Richards KM, et al. Asthma controller medication adherence, risk of exacerbation, and use of rescue agents among Texas Medicaid patients with persistent asthma. J Manag Care Spec Pharm 2015; 21 $1124-1132$.

21 Souverein PC, Koster ES, Colice G, et al. Inhaled corticosteroid adherence patterns in a longitudinal asthma cohort. J Allergy Clin Immunol Pract 2017; 5: 448-456.

22 Papi A, Ryan D, Soriano JB, et al. Relationship of inhaled corticosteroid adherence to asthma exacerbations in patients with moderate-to-severe asthma. J Allergy Clin Immunol Pract 2018; 6: 1989-1998.

23 Bender BG, Pedan A, Varasteh LT. Adherence and persistence with fluticasone propionate/salmeterol combination therapy. J Allergy Clin Immunol 2006; 118: 899-904.

24 Mattke S, Martorell F, Hong SY, et al. Anti-inflammatory medication adherence and cost and utilization of asthma care in a commercially insured population. J Asthma 2010; 47: 323-329.

25 Murphy AC, Proeschal A, Brightling CE, et al. The relationship between clinical outcomes and medication adherence in difficult-to-control asthma. Thorax 2012; 67: 751-753.

26 Ilmarinen P, Tuomisto LE, Niemelä O, et al. Prevalence of patients eligible for anti-IL-5 treatment in a cohort of adult-onset asthma. J Allergy Clin Immunol Pract 2019; 7: 165-174.

27 Kankaanranta H, Ilmarinen P, Kankaanranta T, et al. Seinäjoki Adult Asthma Study (SAAS): a protocol for a 12-year real-life follow-up study of new-onset asthma diagnosed at adult age and treated in primary and specialised care. NPJ Prim Care Respir Med 2015; 25: 15042.

28 Haahtela T, Klaukka T, Koskela K, et al. Asthma programme in Finland: a community problem needs community solutions. Thorax 2001; 56: 806-814.

29 Vähätalo I, Ilmarinen P, Tuomisto LE, et al. Inhaled corticosteroids and asthma control in adult-onset asthma: 12-year follow-up study. Respir Med 2018; 137: 70-76.

30 Tommola M, Ilmarinen P, Tuomisto LE, et al. The effect of smoking on lung function: a clinical study on adult-onset asthma. Eur Respir J 2016; 48: 1298-1306.

31 Williams LK, Joseph CL, Peterson EL, et al. Race-ethnicity, crime, and other factors associated with adherence to inhaled corticosteroids. J Allergy Clin Immunol 2007; 119: 168-175.

32 Ivanova JI, Birnbaum HG, Hsieh M, et al. Adherence to inhaled corticosteroid use and local adverse events in persistent asthma. Am J Manag Care 2008; 14: 801-809. 
33 Wu AC, Butler MG, Li L, et al. Primary adherence to controller medications for asthma is poor. Ann Am Thorac Soc 2015; 12: 161-166.

34 Kitch BT, Paltiel AD, Kuntz KM, et al. A single measure of $\mathrm{FEV}_{1}$ is associated with risk of asthma attacks in long-term follow-up. Chest 2004; 126: 1875-1882.

35 Coumou H, Westerhof GA, de Nijs SB, et al. Predictors of accelerated decline in lung function in adult-onset asthma. Eur Respir J 2018; 51: 1701785.

36 Backer V, Stensen L, Sverrild A, et al. Objective confirmation of asthma diagnosis improves medication adherence. J Asthma 2018; 55: 1262-1268.

37 Hess LM, Raebel MA, Conner DA, et al. Measurement of adherence in pharmacy administrative databases: a proposal for standard definitions and preferred measures. Ann Pharmacother 2006; 40: 1280-1288.

38 Marceau C, Lemière C, Berbiche $\mathrm{D}$, et al. Persistence, adherence, and effectiveness of combination therapy among adult patients with asthma. J Allergy Clin Immunol 2006; 118: 574-581.

39 Blais L, Kettani FZ, Beauchesne MF, et al. New measure of adherence adjusted for prescription patterns: the case of adults with asthma treated with inhaled corticosteroid monotherapy. Ann Pharmacother 2011; 45: 335-341.

40 Hanratty CE, Matthews JG, Arron JR, et al. A randomised pragmatic trial of corticosteroid optimization in severe asthma using a composite biomarker algorithm to adjust corticosteroid dose versus standard care: study protocol for a randomised trial. Trials 2018; 19: 5 . 